\title{
Can We Abandon Our Masks? Deciphering CDC's New Guidelines about Masking in the Era of COVID-19 Pandemic
}

\author{
Sohail Rao, MD, MA, DPhil ${ }^{1,2}$, Khushboo Hemnani ${ }^{3}$, Carlos Arroyo ${ }^{4}$ and Manish Singh, MD, FACS ${ }^{5}$ \\ ${ }^{1}$ Executive Vice President, DHR Health, 5501 S. McColl Road, Edinburg, Texas 78539 and President \\ \& Chief Executive Officer, DHR Health Institute for Research \& Development, 5323 S. McColl Road, \\ Edinburg, Texas 78539. \\ ORCID: https://orcid.org/0000-0001-5027-9992 \\ ${ }^{2}$ Correspondence should be addressed to: Sohail Rao, MD, MA, DPhil., DHR Health Institute for \\ Research \& Development, 5323 S. McColl Road, Edinburg, Texas 78539. Tel: (956) 362-2387. E-mail: \\ s.rao@dhr-rgv.com \\ ${ }^{3}$ Research Academy, DHR Health Institute for Research \& Development, 5323 S. McColl Road, \\ Edinburg, Texas 78539. \\ ORCID: https://orcid.org/0000-0003-4830-4815 \\ ${ }^{4}$ Research Academy, DHR Health Institute for Research \& Development, 5323 S. McColl Road, \\ Edinburg, Texas 78539. \\ ${ }^{5}$ Chief Executive Officer, DHR Health, 5501 S. McColl Road, Edinburg Tx 78539 and DHR Health \\ Bariatric and Metabolic Institute, 500 Raphael Drive, Edinburg, TX 78539 \\ ORCID: Manish Singh: https://orcid.org/0000-0003-4146-3282
}

Received 02/28/2022

Accepted for publication $02 / 28 / 2022$

Published 02/28/2022

Keywords: COVID-19; SARS-CoV-2; CDC, FDA, EUA, Mask

SARS-CoV-2 has infected over 434 million and has claimed the lives of over 5.9 million people worldwide (1). In the United States, over 78.9 million have been infected with SARS-CoV-2 and over 948,000 people have died from COVID-19. Since the issuance of the first Emergency Use Authorization by the US Food and Drug Administration (FDA) for the use of Pfizer/BioNTech COVID-19 mRNA vaccine on December 11, 2020, over 215 million people have been fully vaccinated in United States and over 94 million have received a booster dose $(2,3)$. Despite of these accomplishments, in the last 28 days, in the United States, over 4.6 million people have been infected with this virus with over 61,000 deaths reported (1). COVID-19 is by far the worst pandemic that the world has witnessed and given the recent data, there appears to be no immediate reprieve in sight.

In an attempt to mitigate the spread of COVID-19, CDC has issued several guidelines which included wearing of masks in public gatherings $(4,5)$. Despite of all the evidence that masks are critical to lessen the spread of respiratory viruses such as SARS-CoV-2, the wearing of face masks has become one of the most contentious issues in the United States (6-8). On May 18, 2021, Texas Governor Greg Abbott issued an executive order prohibiting government entities from mandating masks (9). Since then, with the exception of healthcare facilities, and despite $\mathrm{CDC}$ guidelines to the contrary, many organizations have abolished the mandate for indoor masking. Consequently, many states in the United States have or will in the very near future eliminate the mandate for indoor masks as well as in the schools (10).

On Friday, February 25, CDC announced updated guidance on COVID-19 prevention and masking with a new framework for measuring community transmission of the disease. The new guidance means that a substantial portion of the U.S. population will no longer be advised to wear a mask in public and in indoor settings (11). Most of the CDC's changes are based on its community level tool, which measures COVID risks in every US and Puerto Rican counties and helps individuals determine the amount of protection they should use depending on where they live, go 
to work or school, and travel. Considering increasing immunity to the virus and variants like Omicron, the agency overhauled its benchmarks for three community levels: "high" (orange), "medium" (yellow), and "low" (green). Under the new system, 70 percent of Americans are outside of orange zones and can, in theory, stop masking up indoors (Figure 1).

Figure 1: State and County-level COVID-19 Community Levels Interactive Tool Published by the CDC on February 24, 2022 and Updated on February 25, $2022 \quad$ (https://www.cdc.gov/coronavirus/2019ncov/science/community-levels.html)

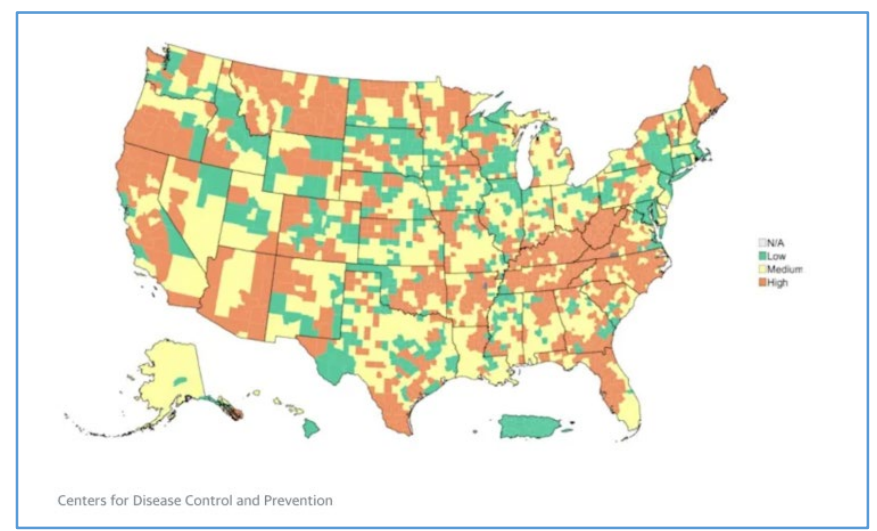

The CDC's guide now only recommends widespread mask use, regardless of vaccination status, in high-risk areas. Previously, this advice also applied to the "substantial" COVID community level, which fell between high and medium. Substantial is no longer marked as a level on the tool. When the community level tool was first launched in early 2021, the categories were defined by case numbers and transmission rates in counties and states. Now the metrics only draw from COVID hospitalizations and occupied inpatient beds in a locality. According to Rochelle Walensky, Director of the CDC "This new framework moves beyond just looking at cases and test positivity to evaluate factors that reflect the severity of disease, including hospitalizations and hospital capacity, and helps to determine whether the level of COVID-19 and severe disease are low, medium, or high in a community. The COVID-19 community levels we are releasing today will inform $\mathrm{CDC}$ measures like masking ... This updated approach focuses on directing our prevention efforts toward protecting people at high risk of severe illness and preventing hospital and health care systems from being overwhelmed."

But even with relaxed precautions, the CDC states that people should take personal risk into account when deciding whether to mask up in public. For example, under the medium community level guidance, the agency says: "If you are immunocompromised or at high risk for severe illness, talk to your healthcare provider about additional precautions, such as wearing masks or respirators indoors in public."
However, it doesn't identify extra masking protocols for adults and older kids who haven't been vaccinated. To date, nearly 14 percent of the US population has not received a single COVID-19 vaccine shot. Despite the shifting guidelines from the $\mathrm{CDC}$ and states, masks are always an option for individuals looking to protect themselves and others from the virus. It is important to note that healthcare facilities, businesses, school districts, transit authorities, and workplaces might have their own indoor masking requirements independent of state mandates that need to be followed.

It must be recognized that all four counties (Hidalgo, Cameron, Willacy, and Starr) in the Rio Grande Valley are considered high risk for COVID-19 transmission. In fact, the four surrounding counties of Kenedy, Brooks, Jim Hogg and Zapata are also considered high risk (Figure 1). For people living in high-risk areas such as the South Texas, CDC has recommended the following (12):

- Wear a well-fitting mask indoors in public, regardless of vaccination status (including in K-12 schools and other indoor community settings)

- If you are immunocompromised or high risk for severe disease:

- Wear a mask or respirator that provides you with greater protection

- Consider avoiding non-essential indoor activities in public where you could be exposed

- Talk to your healthcare provider about whether you need to wear a mask and take other precautions (e.g., testing)

- Have a plan for rapid testing if needed (e.g., having home tests or access to testing)

- Talk to your healthcare provider about whether you are a candidate for treatments like oral antivirals, pre-exposure prophylaxis, and/or monoclonal antibodies

- If you have household or social contact with someone at high risk for severe disease:

- consider self-testing to detect infection before contact

- consider wearing a mask when indoors with them 
- Stay up to date with COVID-19 vaccines and boosters

- Maintain improved ventilation throughout indoor spaces when possible

- Follow CDC recommendations for isolation and quarantine, including getting tested if you are exposed to COVID-19 or have symptoms of COVID-19

We strongly endorse CDC's recommendations and request that people in the Valley use their personal discretion in the use of mask in indoor and public settings. This is particularly important for individuals who are unvaccinated and/or immunocompromised and are at high risk for getting infected with SARS-CoV-2.

\section{Diclosures}

SR declares no conflicts of interest.

$\mathrm{KH}$ declares no conflicts of interest.

CA declares no conflicts of interest.

MS declares no conflicts of interest.

\section{Funding}

The project is funded by a Seed Grant from the DHR Health Institute for Research \& Development

\section{References}

1. COVID-19 dashboard. John Hopkins University of Medicine. 2021. https://coronavirus.jhu.edu/map.html (Accessed February 27, 2022; 13:11 hrs CST)

2. FDA Takes Key Action in Fight Against COVID-19 By Issuing Emergency Use Authorization for First COVID19 Vaccine. December 11, 2020. https://www.fda.gov/news-events/pressannouncements/fda-takes-key-action-fight-againstcovid-19-issuing-emergency-use-authorization-first$\underline{\text { covid-19 }}$

3. COVID-19 vaccination in the United States. COVID-19 Tracker. Centers for Disease Control and Prevention. https://covid.cdc.gov/covid-datatracker/\#vaccinations_vacc-people-onedose-pop-5yr

4. Use and Care of Masks, Centers for Disease Control and Prevention. https://www.cdc.gov/coronavirus/2019ncov/prevent-getting-sick/about-face-

coverings.html?CDC AA refVal=https $\% 3 \mathrm{~A} \% 2 \mathrm{~F} \% 2 \mathrm{Fw}$ ww.cdc.gov $\% 2$ Fcoronavirus $\% 2$ F2019-ncov\%2Fpreventgetting-sick $\% 2 \mathrm{Fcloth}$-face-cover-guidance.html
5. Stop the Spread. Centers for Disease Control and Prevention. https://www.cdc.gov/coronavirus/2019ncov/communication/stop-the-spread.html

6. Li Y, Liang M, Gao L, Ayaz Ahmed M, Uy JP, Cheng C, Zhou Q, Sun C. Face masks to prevent transmission of COVID-19: A systematic review and meta-analysis. Am J Infect Control. 2021 Jul;49(7):900-906. doi: 10.1016/j.ajic.2020.12.007. Epub 2020 Dec 19. PMID: 33347937; PMCID: PMC7748970.

7. Hemmer CJ, Hufert F, Siewert S, Reisinger E. Protection From COVID-19-The Efficacy of Face Masks. Dtsch Arztebl Int. 2021 Feb 5;118(5):59-65. doi: 10.3238/arztebl.m2021.0119. PMID: 33785117; PMCID: PMC8188409.

8. How did face masks become a political issue in America? Guardian. June 29, 2020. https://www.theguardian.com/world/2020/jun/29/facemasks-us-politics-coronavirus

9. Governor Abbott Issues Executive Order 36 Prohibiting Government Entities from Mandating Masks. Office of the Texas Governor - Greg Abbott. May 18, 2021. https://gov.texas.gov/news/post/governor-abbott-issuesexecutive-order-36-prohibiting-government-entitiesfrom-mandating-masks

10. Soon only one U.S. state will still have an indoor mask mandate. CBS News. February 23, 2022, https://www.wltx.com/article/news/health/coronavirus/st ates-drop-indoor-mask-mandates/101-69b72ae7-2b8e45a6-ad47-fbfa9aa0daff

11. New CDC Guidance Ends Mask Recommendation for Most U.S. Counties. National Review. February 25, 2022. https://www.nationalreview.com/news/new-cdcguidance-ends-mask-recommendation-for-most-u-scounties/

12. COVID-19 Community Levels: A measure of the impact of COVID-19 illness on health and healthcare systems. Centers for Disease Control and Prevention. February $25, \quad 2022$. https://www.cdc.gov/coronavirus/2019ncov/science/community-levels.html 